\title{
Fala, leitura e escrita em aplicativos móveis: desafios de uma abordagem discursiva
}

\author{
Alline Mayumi Ribeiro Kobayashi ${ }^{1}$, Fernanda Freire ${ }^{2}$ \\ ${ }^{1}$ Mestranda do Instituto de Estudos da Linguagem - Universidade Estadual de \\ Campinas (UNICAMP)
}

${ }^{2}$ Núcleo de Informática Aplicada à Educação - Universidade Estadual de Campinas (UNICAMP)

allinekobayashi@gmail.com, ffreire@unicamp.br

\begin{abstract}
This article reflects on the use of technology in the acquisition of reading and writing, through the analysis of mobile apps developed for this purpose and presents Lingua de Gato, application for iPad based on theoretical and methodological principles of Discursive Neurolinguistics
\end{abstract}

Resumo. Este artigo apresenta reflexões acerca do uso de tecnologia no processo de aquisição da leitura e da escrita, através da análise de aplicativos móveis voltados para este fim e da apresentação do Língua de Gato, aplicativo para iPad desenvolvido a partir de pressupostos teóricos e metodológicos da Neurolinguística Discursiva (ND).

\section{Introdução}

Aprender a ler e escrever implica o uso de um sistema que se organiza em função de um repertório próprio da língua - de sons e de letras - que recursivamente origina um conjunto de recursos expressivos (palavras) que podem ser combinados de múltiplas maneiras em função de restrições de, pelo menos, dois tipos: (i) aquelas ditadas pelo próprio sistema, (ii) as que resultam da relação desse sistema com outros sistemas não verbais: processos psíquicos, perceptivos e corporais [FREIRE, 2005].

Assim, a escrita convencional do Português Brasileiro (PB) pressupõe compreender o funcionamento do sistema de escrita alfabética: (i) quais letras compõem o repertório da língua (o alfabeto) e em quais sequências elas podem aparecer ( $q$ é sempre seguido de $u$, por exemplo); (ii) quais letras se relacionam a um único som da língua ( $b$ é $/ \mathrm{b} /$ e não /d/, por exemplo) e quais delas podem representar mais de um som ( $s$ pode ser /s/ e /z/, por exemplo); (iii) que existe uma ampla diversidade de grafias usadas em diferentes tipos de materiais impressos ou não (as caligrafias de diferentes pessoas, a letra de imprensa, a letra bastão, etc.). Implica ainda aprender a representação gráfica das letras, a direção (da esquerda para a direita) e a orientação (de cima para baixo) mais usuais com que são registradas à mão [FREIRE, 2011].

Todo esse processo convoca um conjunto de conhecimentos que é posto em ação de maneira coordenada, o que exige o trabalho de vários subsistemas cerebrais 
responsáveis pela atenção, percepção visual e espacial, gestos e linguagem. À medida que a criança aprende a ler e a escrever de forma significativa e contextualizada, isto é, vivenciando práticas de linguagem da vida em sociedade, pouco a pouco, associações de natureza visual, acústica e cinestésica se integram e os processos iniciais de codificação de som/letra (para escrever) e de decodificação letra/som (para ler) se automatizam [LURIA, 1981]. Em outras palavras, "a experiência com a escrita possibilita ao escrevente que ele não pense mais na letra ou no movimento das mãos para escrever uma palavra. Nesse sentido, os processos de leitura e de escrita sofrem o apagamento da representação geométrica da letra; como na fala, apaga-se a propriocepção da produção dos sons. Lemos e escrevemos sentidos" [BORDIN, 2010, p. 43].

A complexidade desse aprendizado, no entanto, nem sempre é (re)conhecida pelo adulto ou pela escola que muitas vezes consideram "que as crianças, apenas por estarem na escola, irão naturalmente aprender a ler e a escrever" [BORDIN, 2010, p. 56]. Os professores, quase sempre respaldados por um método de alfabetização, oferecem às crianças um único caminho para a leitura/escrita, desconsiderando a variedade que existe entre elas, o que demanda outras possibilidades de mediação (material e humana) para este aprendizado [VYGOTSKY, 1984].

Com base nessas considerações, foram analisados alguns aplicativos voltados para a alfabetização disponíveis gratuitamente para iPad e foi desenvolvido o aplicativo Língua de Gato. Seu desenvolvimento impõe, em primeiro lugar, o desafio de aliar uma concepção sociocultural de língua (falada, lida e escrita) às possibilidades tecnológicas oferecidas por dispositivos móveis (figuras, fotografias, áudios, etc.), considerando as singularidades das crianças que com ele interagem, isto é, seus interesses e as relações que (já) são capazes de estabelecer com o sistema alfabético de escrita. Objetiva-se com o seu uso potencializar a mediação coadjuvante (que o aplicativo/dispositivo pode exercer) que pode ser ampliada pela mediação do outro (criança e ou adulto) quando participa da brincadeira da criança com o aplicativo, interferindo, potencialmente, na qualidade da relação da criança com a leitura e a escrita.

\section{O paradigma da Neurolinguística Discursiva e o uso discursivo de tecnologias}

A Neurolinguística Discursiva (ND), iniciada na década de 80 no Instituto de Estudos da Linguagem da Universidade Estadual de Campinas com o trabalho de Coudry [1986], tem como objeto de estudo a linguagem em funcionamento (incluindo a fala, a leitura e a escrita) e sua relação com outras atividades cognitivas (atenção, percepção, memória, raciocínio) em meio à vida em sociedade. Assume um posto de observação predominantemente linguístico [COUDRY e FREIRE, 2010] e sua teorização resulta da articulação de autores que consideram a linguagem, o cérebro e o sujeito como construções socioculturais, portanto, heterogêneos e não constituídos a priori.

A qualificação discursiva reafirma o modo como a linguagem se apresenta: polissêmica e indeterminada por um lado [FRANCHI, 1977/1992], e determinada ideológica e historicamente, por outro [BAKHTIN, 1929/1999]. Essa condição só se dá a conhecer por meio de práticas de uso social de linguagem, razão pela qual a interlocução é um conceito fundamental em seus estudos [COUDRY e FREIRE, 2010]. 
Para sustentar a natureza complexa do funcionamento das línguas naturais, a ND incorpora um modelo de cérebro igualmente complexo com base em conceitos e postulados encontrados em Vygotsky [1934/1984] e Luria [1981], bem como nos estudos neurofisiológicos de Freud [1891/2013].

A palavra, considerada unidade funcional da linguagem [FREUD, 1891/2013], é um complexo associativo de elementos auditivos, visuais e cinestésicos. De acordo com Freud, a representação da palavra é formada a partir da relação entre a imagem de som (registro da palavra ouvida), a imagem de movimento da fala (gestos articulatórios para se pronunciar tal palavra) e a imagem de leitura (imagem visual da palavra escrita). Esta, por sua vez, relaciona-se à imagem de escrita (movimentos das mãos para se escrever). A partir da imagem do som, todo o esquema da representação de palavra se relaciona a um conjunto de representações de várias naturezas (visuais, táteis, acústicas, etc.) que dão significado à palavra ouvida/lida/escrita. Destaca-se neste modelo a centralidade do elemento sonoro nos processos que envolvem a linguagem.

A respeito da leitura/escrita Coudry [2010], com base na relação entre o "velho" e o "novo" postulada por Freud [1891/2013], argumenta que no início da aquisição da leitura e da escrita, a criança se encontra mais na fala (velho) e na leitura (novo) do que na escrita (novo), sendo que a sua variedade de fala pode aproximá-la ou distanciá-la da leitura, considerando que a fala padrão é mais próxima da escrita convencional. Por isso, ler o que os outros escrevem é tão importante para adquirir o sistema da escrita quanto é aprender a falar com a linguagem dos outros, como Freud afirma, servindo como um elo entre o velho (fala) e o novo (escrita).

Segundo a ND, o eixo fala, leitura e escrita demanda uma relação de concomitância: quando a criança aprende a falar repetindo a fala do adulto estabelece uma forte associação entre o acústico (o que ouve: imagem de som) e o motor (gestos articulatórios: imagem de movimento) que ocorrem concomitantemente na tentativa de aproximar a sua fala da fala do outro e, assim, se automatiza, o que pressupõe estar na relação com o outro. É pelo sentido (repetição/recordação do motor e do acústico e suas possíveis combinações) que a criança "entra" na língua de sua cultura onde funcionam e se articulam as dimensões fonológica, sintática, semântica, pragmática.

De forma análoga, quando a criança ganha autonomia em relação à leitura ela lê sentidos e não mais letras ou sucessão de letras que, até então, eram laboriosamente associadas a sons possíveis e que se associavam, por sua vez, a palavras velhas ou novas. É isso o que se observa na leitura silenciosa, que pressupõe a automatização da relação entre o acústico (imagem de som) e o visual (imagem de leitura), dispensando o apoio da voz (imagem de movimento) ou da mão (imagem de escrita).

Em relação ao uso de tecnologias de informação e comunicação (TICs) a ND concebe que nesse tipo de práticas (digitais) de uso social da linguagem estabelecem-se dois tipos de interação relacionados: a interação entre a criança com $o$ computador/dispositivo mediada pelos recursos verbais e não verbais disponíveis na interface da aplicação utilizada e a interação entre a criança e um outro (adulto ou criança) mediada pela língua [FREIRE, 1999/2006]. 
O computador/dispositivo, sensível às ações da criança, responde com feedbacks que assumem a função de uma mediação coadjuvante cuja interpretação pela criança pode ser beneficiada pela mediação do outro [FREIRE, 2012]. A mediação coadjuvante, potencialmente, oferece indícios que ajudam a criança a se manter na interação com a aplicação e a sua qualidade/eficiência depende não só de uma boa usabilidade [NIELSEN, 1993] como também da sua pertinência no contexto da aplicação.

Esse foi um dos desafios do desenvolvimento do Língua de Gato: oferecer feedbacks que promovem uma interação dinâmica entre a criança e o aplicativo e que provocam uma reflexão da criança sobre a língua, em especial, sobre os elementos visuais e acústicos que compõem a palavra.

\section{O paradigma dominante: aplicativos para leitura e escrita}

Como parte das práticas de linguagem desenvolvidas no Centro de Convivência de Linguagens do Instituto de Estudos da Linguagem da Universidade Estadual de Campinas junto a crianças e jovem que apresentam dificuldades escolares relativas ao aprendizado da leitura e escrita, realizam-se diversas atividades envolvendo leitura e escrita mediadas pelo uso de computadores. Observa-se que essas crianças têm uma grande motivação para usar a tecnologia e apresentam desenvoltura para acessar a internet, assistir vídeos, jogar, conversar por meio de chats, pesquisar, participar de redes sociais. No entanto, evitam contextos em que é preciso escrever por não saberem como escrever o que desejam. RM, por exemplo, um menino de $8 \mathrm{a} 9 \mathrm{~m}$ de idade que frequenta o $3^{\circ}$ ano de uma escola pública, sabe qual é a função de um site de busca, sabe acessar o Google e como funciona, sabe dizer qual palavra-chave deve ser escrita, mas não consegue escrevê-la [FREIRE, 2011].

Diante desse cenário, buscou-se por diversos aplicativos para tablets voltados para a aquisição e uso da leitura e da escrita, especialmente aplicativos disponíveis gratuitamente na App Store para iPad, dispositivo que se tinha à disposição na ocasião. Observou-se, então, que a maior parte deles utiliza uma abordagem semelhante à usada em cartilhas de alfabetização, apresentando uma visão da leitura e da escrita que se restringe à codificação/decodificação e memorização. Silva [1998] analisou na década de 90 diferentes softwares que visavam auxiliar no processo de alfabetização voltados para crianças no período pré-escolar e destacou características semelhantes: "o que se viu nos softwares destinados à alfabetização é que se limitam a trazer para a criança uma 'leitura' escolar, desvinculada do contexto e da realidade infantil e que se voltam, basicamente, para a decodificação de signos através da memorização" [SILVA, 1998, p.119].

Com base em Cagiliari [2000], pode-se levantar, ao menos, duas questões importantes e relacionadas entre si que são desconsideradas pelos aplicativos analisados: (i) que a criança sabe falar o português, embora a variedade de sua fala possa não corresponder à variedade padrão ou culta e é capaz de refletir sobre a sua própria língua; (ii) que a fala e a escrita diferem entre si, ainda que a escola e esses aplicativos se apoiem em uma fala artificial na tentativa de aproximar a criança da escrita padrão. Observa-se, assim, uma abordagem que pouco considera o usuário final 
como um sujeito já inserido em um universo letrado, que é um falante da língua e, por isso, é capaz de refletir sobre ela.

O que se sabe sobre o usuário desses aplicativos? Apenas que são crianças, a julgar pelo design infantil das suas telas. Tal abordagem não abre espaço para que os conhecimentos prévios da criança sobre o universo da leitura e da escrita sejam expostos e explorados, limitando as infinitas possibilidades de criação no mundo das letras a um conjunto limitado de palavras (A de Avião, B de Bola, etc.) muitas vezes desinteressante para a criança. Observam-se, assim, atividades "engessadas", pouco flexíveis, ainda comuns em alguns ambientes escolares, reproduzidas na tela do tablet. Esta abordagem se mostra incondizente não só com a natureza da linguagem, como também com as crianças da atual geração, nativas digitais [PRENSKY, 2001], e com a dinamicidade dos vários recursos oferecidos pelos dispositivos móveis (internet, gravação de áudio, vídeo, tecla touch, etc).

A este respeito, Silva [op. cit.] afirma que a característica multimídia da tecnologia (movimentos, imagens, sons e cores) dá ao software uma ilusão de novidade e que “o computador poderá ser o 'novo' inovador que suscitará discussões importantes para o avanço da compreensão, do desenvolvimento e da aprendizagem das crianças sob vários aspectos, ou poderá ser o velho vestindo uma roupagem nova que mascara aspectos já superados no que concerne à alfabetização. Aspectos estes tão arduamente, penosamente, rigorosamente pesquisados através de várias áreas como a linguística, a psicologia, a pedagogia, a psicopedagogia, a história, etc" [SILVA, 1998, p. 101].

Assim, a partir do referencial teórico da ND, surge a questão: como desenvolver softwares voltados para a aquisição e uso da fala, da leitura e da escrita que não sejam apenas o "velho em uma roupagem nova"? O desenvolvimento de softwares para a aquisição e uso da linguagem a partir de uma perspectiva discursiva apresenta-se como um desafio a ser debatido, tanto na área de computação, quanto nas áreas relacionadas à linguagem, tais como linguística, pedagogia, psicologia e fonoaudiologia. Do ponto de vista da educação, existe o desafio de inserir a tecnologia na sala de aula de maneira a enriquecer, de fato, a prática escolar e, do ponto de vista computacional, o desafio está em desenvolver softwares para além do padrão cartilhesco e do senso comum a respeito da língua e da linguagem.

Silva [op. cit.], na conclusão do seu trabalho, apresenta alguns possíveis caminhos para a utilização da tecnologia como auxiliar no processo de aquisição de leitura e escrita de maneira realmente inovadora. Um deles é a aproximação do professor dos conhecimentos tecnológicos e a escolha de softwares apropriados para o que se deseja e outro é a formação de equipes multidisciplinares no desenvolvimento de softwares. O que se pretende com este artigo, então, é dar um primeiro passo nesse caminho através do debate interdisciplinar entre a Linguística e a Computação.

\section{O Língua de Gato}

O Língua de Gato é um aplicativo de criação de jogos de palavras cruzadas para tablets que tem como público alvo crianças em fase de aquisição de leitura e de escrita. As palavras cruzadas são um passatempo clássico em nossa cultura e representam uma prática social de uso de linguagem conhecida de boa parte das crianças. Considerando- 
se o fato de os dispositivos móveis serem ricos em possibilidades de interação e permitirem a captura de fotos, vídeos, áudio e acesso à internet, bem como o fato de as crianças gostarem de tecnologia e apresentarem facilidade em seu manuseio, procuramos otimizar esse potencial com vistas a oferecer uma mediação coadjuvante pertinente e eficaz no contexto de leitura e escrita.

Uma criança de 6 anos que vive no meio urbano assiste tv, joga joguinhos no celular dos pais, vai ao shopping. Por que ela gostaria de aprender a ler e a escrever? Por viver em mundo letrado, a escrita faz parte do seu universo: está presente no comercial de tv, no celular, nas revistas, no cardápio do restaurante. Cagliari afirma que "não basta saber escrever, para escrever. É preciso uma motivação para isso" [2000, p.102]. A escrita tem uma função social e é partir desta função, percebida pouco a pouco pela criança com base nas práticas sociais que vivencia e/ou que presencia outros vivenciando, que surge a sua motivação para aprender a ler e a escrever. A criança quer aprender a escrever para escrever seu próprio nome em seu material escolar, ajudar a sua mãe a fazer a lista de compras ou para usar o celular dos pais da mesma forma que eles o fazem. Ela quer ler para compreender o que aparece registrado na tela enquanto joga vídeo game, o que está escrito nas prateleiras do supermercado ou no letreiro do ônibus. Ler e escrever, portanto, tem a ver com o mundo a nossa volta e é nessa premissa que o Língua de Gato se assenta ao possibilitar a criação de palavras cruzadas com elementos presentes no universo da criança.

O aplicativo foi disponibilizado para download gratuito na App Store em fevereiro de 2016. Sua interação pressupõe dois papéis: o do usuário responsável por criar o jogo de palavras cruzadas (mediador) inserindo um conjunto de palavras e dicas e o do usuário que vai jogar as palavras cruzadas (criança em fase de aquisição de leitura e escrita). Via de regra, o mediador pode ser o professor ou os pais da criança, mas nada impede que o mediador seja a própria criança que cria para si um jogo, para uma outra criança ou, mesmo, para um adulto. Essa troca de papéis, inclusive, pode ser bastante interessante em termos de exploração da língua e dos recursos do tablet.

A versão atual do aplicativo, v. 1.0.1, apresenta 3 possibilidades de ação (Figura 1): criar um jogo de palavras cruzadas, jogar uma palavra-cruzada gerada aleatoriamente a partir de palavras inseridas pelo mediador e jogar um jogo salvo.
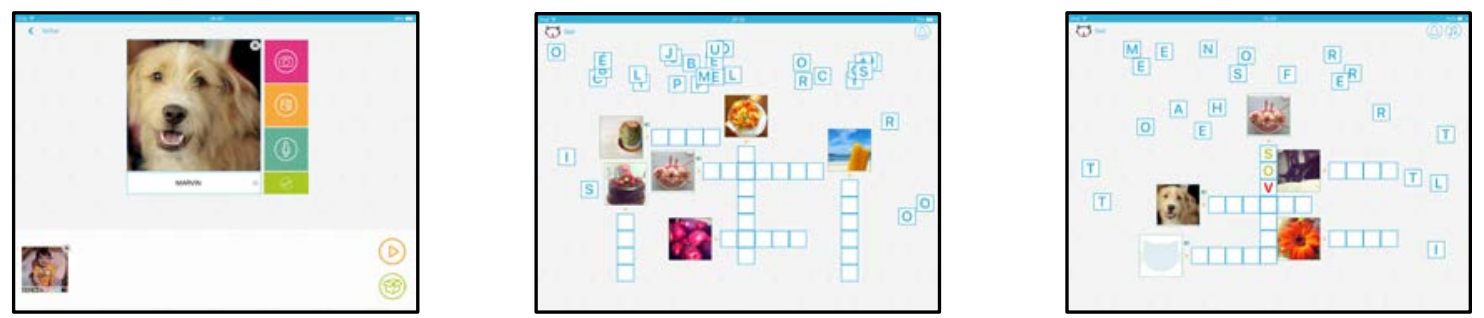

Figura 1. Telas do Língua de Gato, da esquerda para a direita: tela de criação do jogo, tela do jogo e feedback do aplicativo quando a criança seleciona uma letra errada.

Cada palavra inserida para a criação de um jogo possui 2 tipos de "dicas": visuais e/ou auditivas. Por exemplo, ao adicionar a palavra sorvete pode-se inserir uma dica visual tirando uma foto de um sorvete ou selecionando uma foto a partir da galeria 
de fotos do dispositivo e pode-se também gravar o áudio do mediador dizendo a palavra sorvete. A inclusão da dica auditiva tem o propósito de relacionar a fala e a escrita, uma vez que o que se diz não é o exatamente o que se escreve. Tal fato é um complicador para as crianças em fase inicial de aquisição da escrita. Inseridas as palavras e suas respectivas dicas na tela de criação de jogo, o mediador pode salvar este jogo para torná-lo acessível posteriormente ou apenas jogá-lo naquele momento.

A tela de jogo é formada pelas cruzadas e pela imagem de cada dica. Quando uma dica é clicada, a imagem é ampliada e, caso possua uma dica auditiva, o som do áudio é reproduzido. A disposição das palavras na cruzada é gerada aleatoriamente toda vez que a tela do jogo é carregada.

Para completar a cruzada a criança deve arrastar a letras que aparecem distribuídas pelo "tabuleiro" do jogo. Nesta primeira versão do aplicativo todo o conjunto de letras disponível é utilizado para completar o jogo. Ao arrastar uma letra para uma determinada posição da cruzada o dispositivo oferece feedbacks visual (escreve em vermelho, como mostra a Figura 1) e auditivo para indicar se a letra foi ou não colocada na posição correta. A interface do aplicativo tem algumas especificidades quando comparado ao de outros jogos de palavras cruzadas, como mostra a Figura 2.
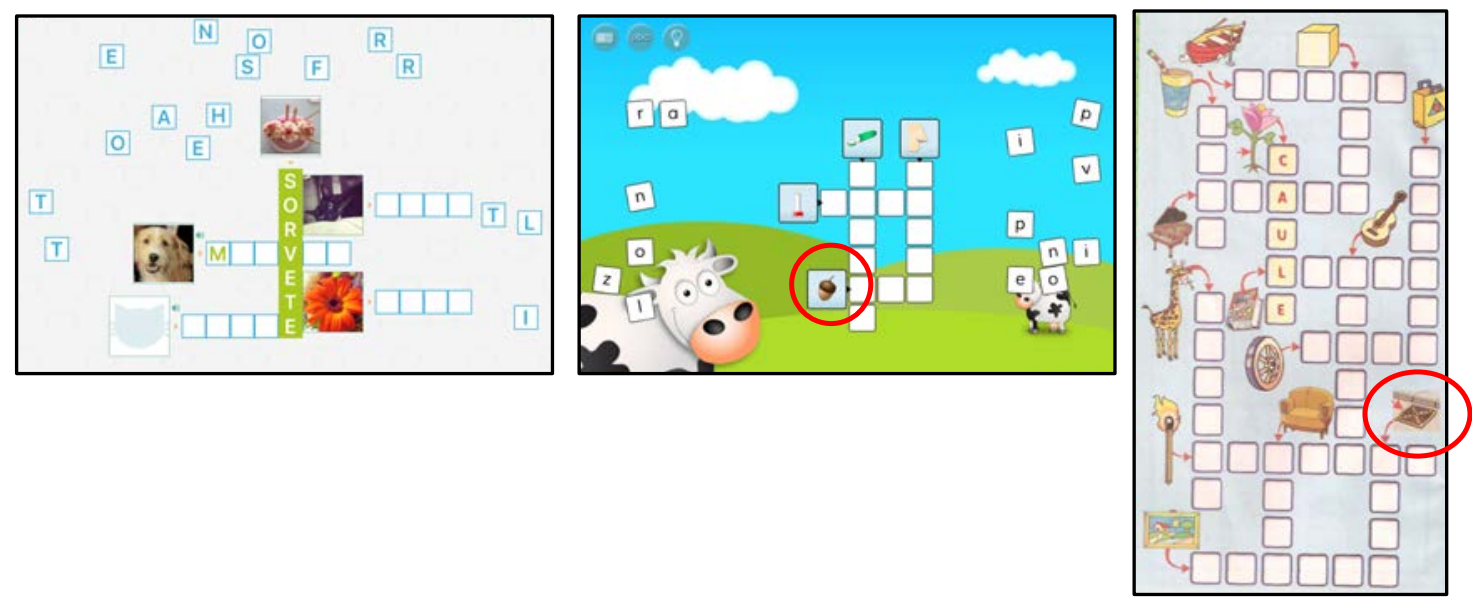

Figura 2. Da esquerda para a direita: aplicativos Língua de Gato e Happi Spells (iPad) e palavras cruzadas em papel (Revista Picolé n.35, Coquetel).

A primeira característica a ser destacada, já mencionada anteriormente, é o fato de as dicas visuais do Língua de Gato serem fotos de elementos do universo da criança, o que confere ao jogo um caráter pessoal, especial, podendo afetar positivamente a motivação da criança. As dicas visuais, por exemplo, podem ser fotografias de seus amigos ou de sua família. Além disso, pelo fato de as dicas visuais serem fotografias e não desenhos, mantém-se as características reais do que se pretende representar, evitando, assim, ambiguidades. Veja-se, por exemplo, na Figura 2, como é difícil perceber visualmente a "noz" do jogo Happi Spells ou o ralo da Revista Coquetel (destacadas com um círculo).

Além disso, pelo fato de as palavras serem customizáveis, pode-se evitar a presença de imagens/palavras pouco familiares à criança que poderiam funcionar como uma dificuldade não desejável para os iniciantes na escrita. A maioria das crianças 
brasileiras, por exemplo, pode não identificar o desenho da "noz" como tal, tanto pelo traçado do desenho quanto pelo fato de não conhecer a palavra. Isto não quer dizer que o jogo deva conter apenas palavras já conhecidas pela criança, mas sim que cabe ao mediador determinar quais imagens e palavras são interessantes para determinada criança. Quando se deseja, por exemplo, expandir o vocabulário, pode-se inserir fotografias de objetos que a criança ainda não conhece. Neste caso, está em relação o velho e o novo: quando a criança já conhece a palavra pela fala, mas não conhece a sua imagem ou, ao contrário, quando a criança conhece a imagem, mas não sabe o seu nome: o velho em cada um dos dois casos pode facilitar o aprendizado do novo.

Outro aspecto a ser destacado na interface do Língua de Gato e também presente no aplicativo Happi Spells é a presença da imagem acústica das palavras, ausente na versão em papel. Conforme detalhado na seção 2 , o processo de escrita tem como base a fala e, para escrever, deve existir um vai e vem de relações entre o acústico, o visual e o motor. Ao jogar qualquer um dos jogos da Figura 2 a criança olha a imagem da palavra a ser escrita, identifica-a e diz (nem que seja mentalmente) o que escrever. Quando a dica acústica está presente a criança pode comparar a sua fala com a fala do outro, o que pode gerar uma reflexão importante para os aprendizes sobre diferentes pronúncias, mais ou menos próximas da escrita convencional. Por exemplo, a criança pode falar pipinu, mas escreve-se pepino.

Uma vez que a criança já sabe o que deverá escrever, no jogo tradicional em papel, ela passa a refletir sobre a relação som/letra e, então, com base na memória que tem das letras do alfabeto, deve selecionar qual letra deve escrever (imagem visual) e, então, como escrevê-la (imagem cinestésica da escrita no papel). Caso sobre ou falte quadradinhos no jogo, a criança perceberá que não fez as seleções adequadas, seja da palavra, seja das letras que a compõem. No Língua de Gato (e também no Happi Spells) este processo torna-se mais simples, uma vez que a representação visual das letras já está dada: ela não precisa resgatar mentalmente qual o formato de determinada letra e como traçá-la, mas deve identificar a letra desejada dentre as letras disponíveis na tela e arrastá-la até a posição desejada.

O feedback oferecido pelo aplicativo, caso mova uma letra para uma posição inadequada, difere nos dois aplicativos. No Língua de Gato é possível que a criança mova uma peça para um local inadequado, com o intuito de fazê-la reler/rever o que está tentando escrever. Neste caso, a letra assumirá a cor vermelha, diferente do padrão que é verde, como um indicativo de que há alguma coisa a ser revista. No Happi Spells o movimento de uma letra "errada" não é possível: a criança tenta posicioná-la no jogo, mas ela retorna ao seu lugar de origem na tela. Diferente da abordagem comumente presente no ambiente escolar e nos aplicativos destinados à escrita/leitura, o erro no Língua de Gato não é visto como problema, mas, sim, como uma possibilidade de reflexão sobre as hipóteses possíveis para a escrita de determinada palavra. Para a ND, as tentativas e hesitações da criança que está aprendendo a ler e a escrever, denominadas de atividades epilinguísticas [COUDRY, 1986], são importantes para o aprendizado e, para tal, a criança precisa se colocar na posição de leitora de sua própria produção com o objetivo de refletir sobre ela e corrigi-la.

\subsection{Desenvolvimentos futuros}


Atualmente, o Língua de Gato está em fase de testes com usuários para coletar experiências acerca da interação, interface e jogabilidade. A coleta dessas informações busca não apenas reavaliar tais pontos, mas também construir uma estratégia de jogabilidade, atualmente inexistente, para que ele se torne mais interessante e atraente.

Para possibilitar o trabalho com a linguagem da maneira mais abrangente possível e explorar os recursos tecnológicos disponíveis, algumas funcionalidades serão incluídas. Uma delas é dar à criança um feedback sonoro diferenciado da palavra escrita, isto é, a sua leitura automática. É importante que a criança possa comparar a leitura do aplicativo com a imagem de som que ela pretendeu escrever. Encontra-se aqui uma questão técnica a ser estudada: a leitura automática da palavra não poderá ser mecânica a ponto de interferir na prosódia e, com isso, na compreensão de seu sentido.

A respeito da tríade sonoro/visual/motor presente na leitura e escrita, seria desejável a inclusão de atividades que explorem também o aspecto motor da escrita. Serão estudadas possibilidades de desenvolvimento de tais funcionalidades, porém ainda não se sabe se tais funcionalidades serão incluídas dentro do jogo de palavras cruzadas ou em outra modalidade de jogo.

Pretende-se, também, dar ao mediador maior poder de customização sobre o aplicativo a partir de uma tela de configuração, atualmente inexistente, na qual ele poderá escolher entre diferentes tipos de fontes para as letras do jogo e se elas serão maiúsculas ou minúsculas. Desta maneira, o mediador poderá determinar a imagem visual que mais se adequa ao que se deseja trabalhar. Outra possiblidade será a escolha do número de letras do alfabeto disponíveis para se concluir o jogo.

\section{Considerações finais}

Com base em uma concepção ampla de linguagem proposta pela ND que considera tanto seu aspecto interno, constituinte e construtor do sujeito [FRANCHI, 1977/1992], quanto externo, na relação do sujeito com o outro e com o mundo, inseridos num contexto sócio histórico, buscou-se, por um lado, identificar as abordagens sobre leitura e escrita utilizadas por boa parte dos aplicativos disponíveis para iPad e, por outro, apresentar os desafios (e as razões) envolvidos no desenvolvimento do aplicativo Lingua de Gato.

A utilização de diferentes aplicativos voltados para a aquisição da leitura e da escrita revelou uma visão de linguagem restrita que desconsidera o fato de a criança ser um falante da língua e seu conhecimento como tal; desconsidera, ainda, o fato de a leitura e a escrita serem práticas sociais cujo aprendizado está diretamente relacionado à interação da criança com o mundo a sua volta.

Quando se considera a linguagem como decorrente da relação do sujeito com o mundo e com o outro, o desenvolvimento de um aplicativo voltado para o processo de aquisição da leitura e escrita precisa considerar o usuário final como um sujeito único, com motivações específicas para entrar no mundo das letras e que trilha um caminho também único até tonar-se um leitor/escrevente autônomo. Desta maneira, o maior desafio no desenvolvimento de um aplicativo para este fim é possibilitar que o sujeito ali se expresse e se veja, ou seja, que o aplicativo reflita a relação singular do sujeito 
com a linguagem. Para tal, deve-se compreender que o aplicativo não será uma solução que irá alfabetizar alguém, mas sim mais um mediador nesse processo que necessita da interação da criança com o mundo e com o outro.

\section{Referências}

Bakhtin, M. (1929/1999). Marxismo e Filosofia da Linguagem, Hucitec, São Paulo.

Bordin, S. S. B. (2010). Fala, Leitura e Escrita: encontro entre sujeitos, Tese de Doutorado, Universidade Estadual de Campinas. Campinas.

Cagliari, L. (2000). Alfabetização e Linguística, Editora Scipione, São Paulo.

Coudry, M. I. H. (1986). Diário de Narciso: discurso e afasia. Tese de Doutorado, Universidade Estadual de Campinas. Campinas.

Coudry, M. I. H. (2010). Caminhos da Neurolinguística Discursiva: o velho e novo. In: Coudry, M. I. H.; Freire, F. M. P.; Andrade, M. L.; SILVA, M. A. (orgs.). Caminhos da Neurolinguística Discursiva: teorização e práticas com a linguagem, p. 23-48, Mercado de Letras, Campinas.

Coudry, M. I. H. e Freire, F. M. P. (2010). Pressupostos teórico-clínicos da Neurolinguística Discursiva (ND). In: Coudry, M. I. H.; Freire, F. M. P.; Andrade, M. L.; SILVA, M. A. (orgs.). Caminhos da Neurolinguística Discursiva: teorização e práticas com a linguagem, p. 23-48, Mercado de Letras, Campinas.

Franchi, C. (1977/1992). Linguagem - Atividade Constitutiva. In: Cadernos de Estudos Lingüísticos, p. 9-39, v. 22, Campinas.

Freire, F. M. P. (2005) Agenda Mágica: linguagem e memória, Tese de Doutorado, Universidade Estadual de Campinas. Campinas.

Freire, F. M. P. (2006) Enunciação e Discurso: a linguagem de programação Logo no discurso do afásico. Mercado de Letras (1999), Campinas.

Freire, F. M. P. (2011). Práticas digitais informais e leitura/escrita formais. In: Anais do XVI Congresso Internacional de la Asociación de Lingüística y Filología de la América Latina (ALFAL), p. 1-10, Alcalá de Henares.

Freire, F. M. P. (2012) Escola e tecnologia: um olhar discursivo sobre essa complexa relação. In: Livro de Atas do II Congresso Internacional TIC e Educação, v. 1, p. 513-533, Lisboa.

Freud, S. (1891/2013). Sobre a concepção das afasias: um estudo crítico. Tradução de Emiliano de Brito Rossi, Editora Autêntica, Belo Horizonte.

Luria, A. R. (1981). Fundamentos de Neuropsicologia. Cultrix, São Paulo.

Nielsen, J. (1993). Usability Engineering. Academic Press, Cambridge.

Prensky, M. (2001). Digital Natives, Digital Immigrants, MCB University Press, Bradford.

Silva, M. R. G. (1998). O computador e a alfabetização: estudo das concepções subjacentes nos softwares para a Educação Infantil, Dissertação de Mestrado, Universidade Federal de Santa Catarina. Florianópolis.

Vygotsky, L. S. (1934/1984). A Formação Social da Mente, Martins Fontes, São Paulo. 